\title{
Reliability and validity of a scale for measurement of trunk mobility in Parkinson's disease
}

\author{
Trunk Mobility Scale
}

\author{
Clarissa R.C. Franco', Paula Leão², Raquel Townsend³, Carlos R.M. Rieder ${ }^{4}$
}

\begin{abstract}
Axial rigidity is an important motor manifestation in Parkinson's disease (PD). Trunk mobility impairment can cause gait, balance and postural problems. However, only few instruments analyze the trunk mobility in PD patients. The aim of this study is to present a new Trunk Mobility Scale (TMS) and its validation in PD. The TMS constituted of dynamic tests involving trunk movements in sagittal, transversal and coronal planes. Ninety eight PD patients and 31 normal controls were analyzed. A strong correlation was found between the TMS scores and the Hoehn \& Yahr staging scale ( $r: 0.72 ; p<0.01)$, motor Unified Parkinson's Disease Rating Scale ( $r: 0.84 ; p<0.01)$ and Schwab and England Activities of Daily Living $(r:-0.72 ; p<0.01)$. The scale showed a satisfactory reliability rate $\left(\alpha_{\text {Cronbach }}: 0.85\right.$, ICC: 099). TMS is a simple and reliable instrument to evaluate trunk mobility impairment in patients with PD.
\end{abstract}

Key words: Parkinson's disease, Trunk Mobility Scale, rigidity.

Confiabilidade e validade de uma escala de mensuração da mobilidade do tronco na doença de Parkinson: Escala de Mobilidade de Tronco

\section{RESUMO}

Rigidez axial é importante manifestação motora na doença de Parkinson (DP). Prejuízos na mobilidade do tronco podem ocasionar problemas na marcha, equilíbrio e postura. No entanto, poucos instrumentos analisam a mobilidade do tronco em pacientes com DP. O objetivo deste estudo é apresentar uma nova Escala de Mobilidade do Tronco (TMS) e sua validação na DP. A TMS é constituída de provas dinâmicas que envolvem os movimentos do tronco no plano sagital, transversal e coronal. Noventa e oito pacientes com DP e 31 controles normais foram analisados. Uma forte correlação foi encontrada entre os escores do TMS e os do Hoehn \& Yahr Staging Scale (r: 0,72; $<<0,01)$, Unified Parkinson's Disease Rating Scale ( $r: 0,84 ; p<0,01)$ e Schwab and England England Activities of Daily Living $(r:-0,72, p<0,01)$. A escala mostrou uma taxa de confiabilidade satisfatória ( $\alpha_{\text {Cronbach }}$ :, 85 ; ICC: 099). TMS é um instrumento simples e confiável para avaliar comprometimentos da mobilidade de tronco em pacientes com DP.

Palavras-chave: doença de Parkinson, Escala de Mobilidade de Tronco, rigidez.

Parkinson's disease (PD) is a degenerative and progressive disease that presents bradykinesia, tremor at rest, postural instability and rigidity as main motor manifestations ${ }^{1-3}$. Axial rigidity can be respon- sible for functional impairments of gait, balance and motor control ${ }^{4-6}$. Although axial rigidity is one incapacitating characteristics of disease, most methods for assessing muscle tone have focused on ap-

\section{Conflicts of interest}

The authors report no conflict of interest 
pendicular rigidity including the arms, wrists, and knees. Many researchers suggest that axial rigidity may be responsible for trunk en bloc turning movement, characteristic in patients with $\mathrm{PD}^{7-9}$. Furthermore, alteration in tonus and mobility of trunk may affect the daily activities and the quality of life of PD patients. Axial rigidity may cause difficulty in rolling over in bed and standing up when in sitting position ${ }^{5,6,10}$.

In order to monitor the disease progress or even the effectiveness of a certain medication or physiotherapeutic action, fast assessment mechanism of easy clinical access are required to help health professionals ${ }^{2,11,12}$. Most available studies analyze the rigidity of limbs, neglecting however, the movement alterations that the axial rigidity causes to a patient with $\mathrm{PD}^{13,14}$. Besides insufficient literature on that, the tools that assess the trunk mobility are scarce and restricted to the movement quantification in the transversal plane (rotation) $)^{15-17}$. Although some scales associate the rotation assessment with forward inclination measurements (sagittal plane) ${ }^{18}$, flexion measurement is not part of any integrated scale that quantifies the two movement planes in a single instrument.

Scales for the trunk movement assessment in patients with PD include the Functional Rotation Test $(\mathrm{FRT})^{15}$ and the Functional Axial Rotation (FAR) ${ }^{18}$. Both scales require a special infrastructure, such as rooms with graduation marks on the walls, referential points attached to patients and/or tripods to enable the execution of tasks and measurements, which makes them of difficult clinical utilization. Another important limitation of the FRT scale is that it is not easy to collect data from individuals with accentuated tremor at rest and dyskinesia, as these patients have difficulty in keeping the final position required for such measurement ${ }^{16}$. On the other hand the FAR scale evaluates only one movement plane (transversal) and it is not predictor of functionality ${ }^{18}$. The Trunk Impairment Scale (TIS) was validated to $\mathrm{PD}^{9}$. However, this scale was originally created to evaluate the static balance, the dynamic balance and the coordination in patients with cerebral vascular accident and one limitation of this scale is that it does not evaluate the sagittal plane.

This study aims to create and validate an instrument for trunk mobility evaluation of patients with PD. The instrument, named Trunk Mobility Scale (TMS), evaluates trunk movement in all planes (sagittal, coronal and transversal).

\section{METHOD}

The study involved 98 patients with diagnosis of PD according to the criteria of the UK Parkinson's Disease Society Brain Bank ${ }^{19}$. Patients were recruited from the Movement Disorder Clinic of Hospital de Clínicas de Porto Alegre RS, Brazil. The study had the participation of 31 controls, healthy subjects, recruited for this study among patient's relatives and companions. Exclusion criteria included diagnosis of other neurological diseases (ataxia, cerebral vascular accident, dementia etc.), orthopedic surgeries (spine arthrodesis at any level) and traumatological and orthopedic diseases (fracture, arthrosis), that prevented the tests from being performed.

\section{Procedures}

Patients in the study were evaluated using Unified Parkinson's Disease Rating Scale-III (UPDRS-III) ${ }^{20}$, Schwab and England Activities of Daily Living (S\&E $)^{21}$ and Hoehn \& Yahr scale $(H \& Y)^{22}$. Disease duration, gender and age were controlled.

The TMS was based on six dynamic tests that involve the trunk movements in the sagittal plane (extension/flexion), transversal (rotation) and coronal (side inclination) and one static test that evaluated the sitting posture. The tests were performed with the patient sitting on a chair, with no arm support, feet on the floor and the back kept $10 \mathrm{~cm}$ from the chair. All movements were previously demonstrated to the patient by the study investigator.

Scores of dynamic items ranges from 0 to 3 . The patient that performs the movement with no compensation receives score 0 . The patient that is unable to make the requested movement receives score 3 . Scores 1 and 2 are attributed to individuals that perform the movements, but with compensations. The score is 1 for small compensations, and 2 for great compensations. Great compensations are exaggerated movements, easily noticed by an investigator (for instance, when inclining sideways, the patient associate trunk rotation and/or flexion and/or extension movements). Small compensations are subtle movements, but that are present when the movement is performed. In the static aspect, the sitting posture analysis may range from 0 (upright sitting position) to 4 (strong flexion and/or side inclination with extreme posture abnormality). In the other aspects, the posture may be severely, moderately and slightly inclined, items 3,2 and 1 , respectively.

A neurologist performed the UPDRS-III, S\&E and $H \& Y$ scales. Two other investigators simultaneously recorded the TMS scores. The investigators were blind regarding the results obtained by one another in the TMS and were previously trained on how to apply the scales.

All patients and participants signed the Consent Term. This study was approved by the Research and Ethics Committee of the involved institution (HCPA).

\section{Statistical analysis}

The categorical variables were described through absolute and relative frequencies. The quantitative variables 
Table 1. Clinical characteristics of patients with Parkinson's disease (PD) and controls.

\begin{tabular}{|c|c|c|c|}
\hline & & $\begin{array}{l}\text { PD group } \\
(n=98)\end{array}$ & $\begin{array}{c}\text { Control } \\
\text { group }(n=31)\end{array}$ \\
\hline \multicolumn{2}{|l|}{ Age } & $67.23( \pm 11.25)^{*}$ & $60.90( \pm 11.57)^{*}$ \\
\hline \multirow[t]{2}{*}{ Gender } & Female & $48(49 \%)$ & $24(77 \%)$ \\
\hline & Male & $50(51 \%)$ & $7(22 \%)$ \\
\hline \multicolumn{2}{|c|}{ Diagnosis (years) } & $7.88( \pm 5.22)$ & NA \\
\hline \multicolumn{4}{|l|}{ Scales } \\
\hline \multicolumn{2}{|l|}{ TMS } & $6.75( \pm 4.92)^{*}$ & $2.64( \pm 2.43)^{*}$ \\
\hline \multicolumn{2}{|c|}{ UPDRS-III } & $31.84( \pm 24.09)$ & NA \\
\hline \multicolumn{2}{|l|}{ H\&Y } & $2.66( \pm 1.12)$ & NA \\
\hline \multicolumn{2}{|l|}{ S\&E } & $79.18( \pm 19.98)$ & NA \\
\hline
\end{tabular}

TMS: Trunk Mobility Scale; UPDRS-III: Unified Parkinson's Disease Rating Scale; H\&Y: Hoehn and Yahr Scales; S\&E: Schwab \& England Activities of Daily Living Scale; NA: not assessed; ${ }^{*} p<0.01$.

were described through mean and standard deviation values. The criteria validation, i.e., the comparison to gold standards, was performed through the correlation with the scales: H\&Y, UPDRS-III and S\&E, and the instrument proposed through Spearman's Correlation Coefficient and Pearson's Correlation Coefficient $\left(r_{s}\right.$ and $r$, respectively). A factorial analysis was performed to verify the specific domains of the scale. In order to assess the scale reliability, the internal consistence of the instrument was measured using Cronbach's alpha $\left(\alpha_{\text {Cronbach }}\right)$ and the investigators' agreement through the Intra-Class Correlation Coefficient (ICC). The significance level adopted in the study was $\mathrm{p}<0.05$ and the application program SPSS (Statistical Package for Social Sciences) version 14.0 performed the analyses.

\section{RESULTS}

Ninety-eight patients with PD were assessed, 48 of them were female (49\%) and 50 were male (51\%), presenting mean age of $67.23( \pm 11.25)$ and disease time of $7.88( \pm 5.22)$ years. The study also assessed 31 controls: 24 women (77\%) and 7 men (22\%), who presented mean age of $60.90( \pm 11.57)$ years. Table 1 shows the clinical characteristics of the sample.

Age and gender did not have influence on the TMS scores in patients and controls. The relation between age and the TMS was meaningless, with correlation rate of $r=0.07$. Gender did not show any influence on the TMS results either. Women obtained mean score of 5.61 $( \pm 4.70)$ and men obtained mean score of $5.95( \pm 4.91)$ in the TMS scale $(\mathrm{p}=0.69)$.

\section{Reliability}

The reliability rate between examiners of the proposed scale was very significant, with ICC of 0.99 . The
Table 2. Reliability - Cronbach's Alpha for Trunk Mobility Scale Items.

\begin{tabular}{|c|c|c|c|}
\hline & ICC & $\alpha$ Cronbach & $\begin{array}{l}\alpha \text { Cronbach if } \\
\text { item excluded }\end{array}$ \\
\hline Trunk Mobility Scale & 0.99 & 0.85 & \\
\hline Inclination to righ & & & 0.82 \\
\hline Inclination to left & & & 0.82 \\
\hline Rotation to right & & & 0.84 \\
\hline Rotation to left & & & 0.84 \\
\hline Flexion & & & 0.84 \\
\hline Extention & & & 0.85 \\
\hline Sitting & & & 0.83 \\
\hline
\end{tabular}

Table 3. Factorial analysis of the Trunk Mobility Scale with rotation.

\begin{tabular}{lcc}
\hline & 1 & 2 \\
\hline Values & 3.21 & 1.99 \\
\% variation & 45.89 & 28.46 \\
\% accumulative & 45.89 & 74.35 \\
Trunk Mobility Scale & & \\
Inclination to right & 0.86 & 0.23 \\
Inclination to left & 0.87 & 0.20 \\
Rotation to right & 0.18 & 0.94 \\
Rotation to left & 0.22 & 0.93 \\
Flexion & 0.75 & 0.15 \\
Extension & 0.75 & 0.06 \\
Sitting & 0.71 & 0.34 \\
\hline
\end{tabular}

Table 4. Correlation between the Trunk Mobility Scale and UPDRS-III items.

\begin{tabular}{ll}
\hline UPDRS-III & TMS \\
\hline Speech & $0.56^{*}$ \\
Facial expression & $0.56^{*}$ \\
Rest tremor & $0.52^{*}$ \\
Action tremor & $0.41^{*}$ \\
Rigidity & $0.89^{*}$ \\
Finger taps & $0.64^{*}$ \\
Hand movements & $0.66^{*}$ \\
Pronation/supination of hands & $0.63^{*}$ \\
Leg agility & $0.70^{*}$ \\
Arising from chair & $0.60^{*}$ \\
Posture & $0.65^{*}$ \\
Gait & $0.65^{*}$ \\
Postural stability & $0.50^{*}$ \\
Bradykinesia & $0.65^{*}$ \\
\hline UPDRS-III: Unified Parkinson's Disease Rating Scale; TMS: Trunk Mobility \\
Scale. ${ }^{*}$ < 0.01.
\end{tabular}



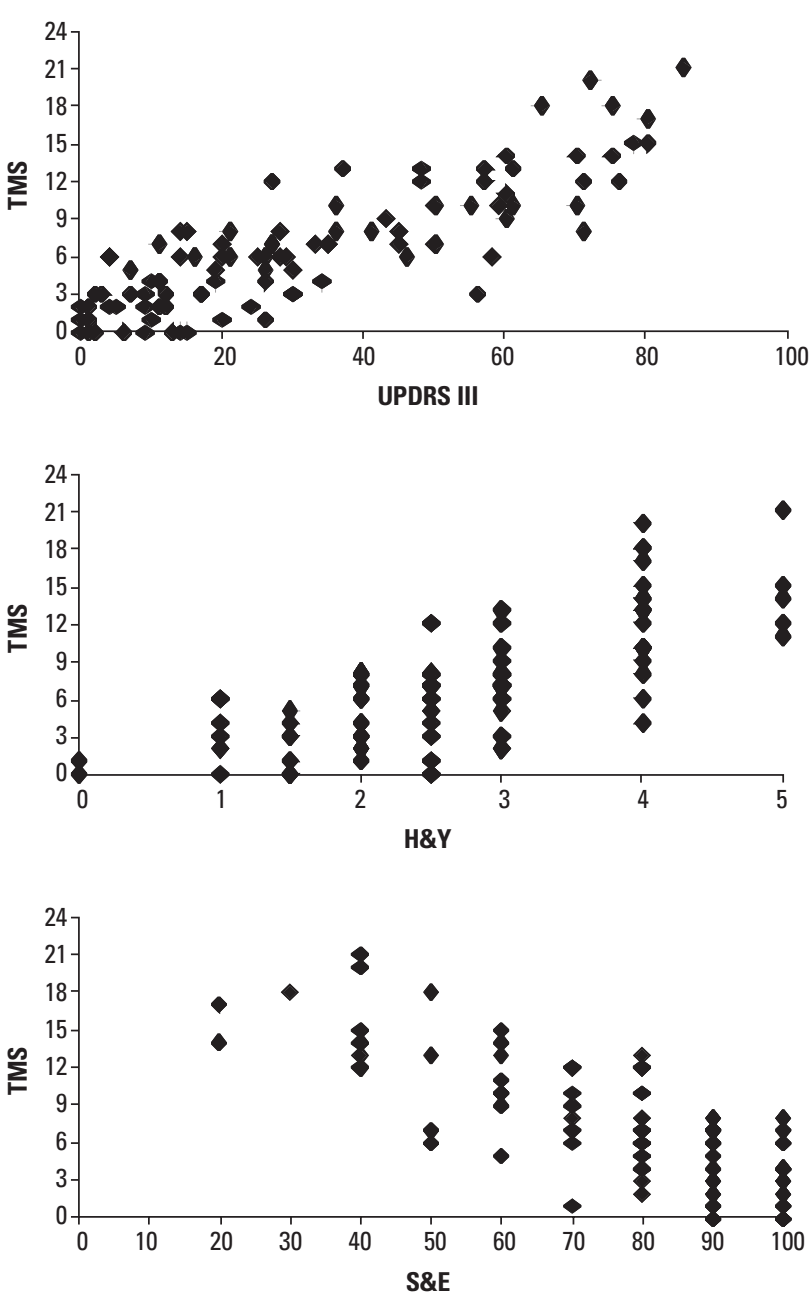

Fig 1. Correlation between the Trunk Mobility Scale (TMS) and Unified Parkinson's Disease Rating Scale III (UPDRS-III), Hoehn and Yahr Scales (H\&Y) and Schwab \& England Activities of Daily Living Scale (S\&E). Coefficients: $0.84,0.72$ and -0.72 , respectively, all with $p<0.01$.

internal consistence was high, with $\alpha_{\text {Cronbach }}$ of 0.85 (Table 2). This value did not change with the exclusion of any scale item.

\section{Internal validation}

The factorial analysis showed that the scale presents two domains, with values over 1 , which correspond to $74.35 \%$ of the total variance. Side inclination, flexion and extension movements and the static analysis of the sitting posture present similar values in the factorial analysis. Therefore, all these variables are interrelated. The second domain was established by the rotation movements, which showed a different tendency from the others. Table 3 shows the factorial analysis data.

\section{External validation}

There was a high correlation between TMS and the UPDRS-III, H\&Y and S\&E scales, with $\mathrm{r}: 0.84,0.72$ and
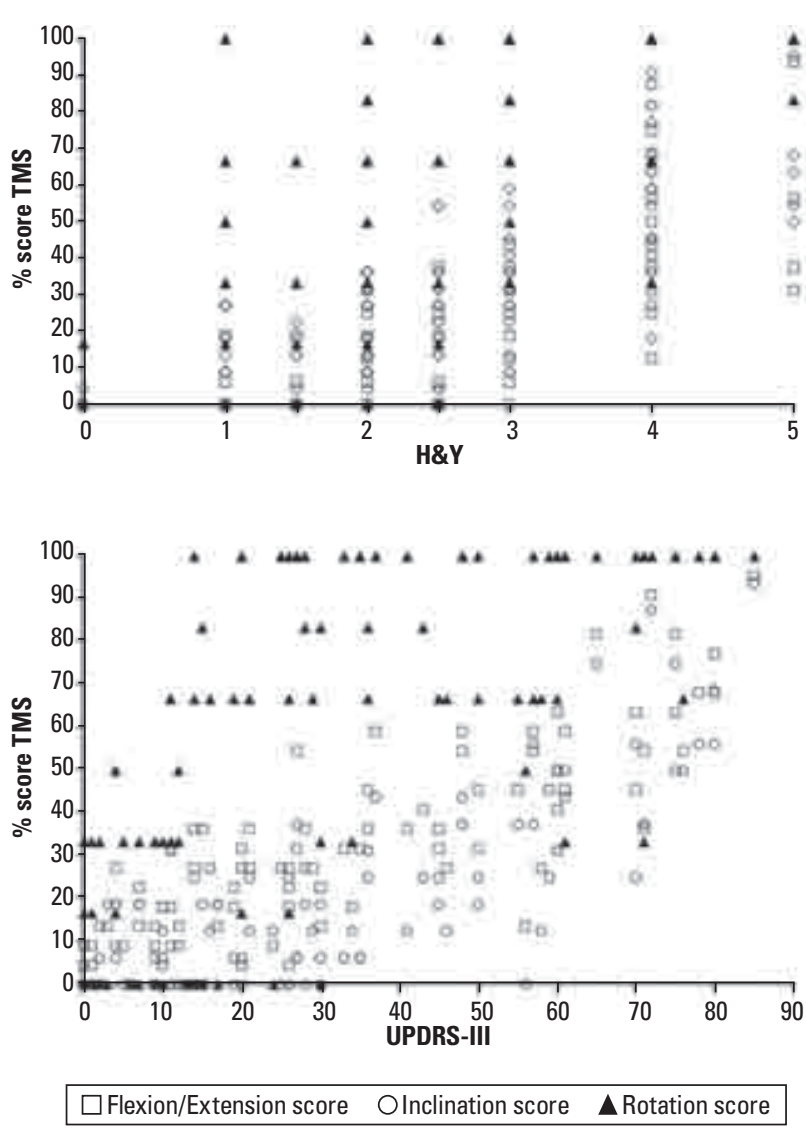

Fig 2. Correlation between the different planes of evaluation of Trunk Mobility Scale (TMS) and motor Unified Parkinson's Disease Rating Scale (UPDRS III) and Hoehn and Yahr Scales (H\&Y).

-0.72 , respectively (Fig 1 ). Fig 2 shows the analysis of different planes of trunk movement (rotation, lateral inclinations and flexion/extension) and their correlation with UPDRSIII and H\&Y. The score in those movement modalities was present as percentage of total score in TMS (for instance, rotation score $=$ score in rotation $\times 100 /$ total TMS score) .

The lateral inclinations and flexion/extension movements were correlated with UPDRS-III and H\&Y scores. Thus, the decrease in lateral inclinations and flexion/extension movements was related with functional impairment, evaluated by UPDRS-III and H\&Y. The rotation movement, however, exhibited high scores (higher impairment), even with lower UPDRS-III and H\&Y scores.

Concerning the specific items of UPDRS-III, the TMS demonstrated an important correlation with "rigidity" (item 22 of UPDRS) (r: 0.89; $<<0.01$ ) and a moderate-to-high correlation regarding the other items $(\mathrm{p}<0.01)$ (Table 4). The weaker correlations were between TMS and tremor scores.

\section{DISCUSSION}

Trunk movement alteration, present in PD, may lead to motor impairment. The axial rigidity seems to en- 
hance the loss of functionality in patients with PD in the execution of daily activities, such as walk, change direction while walking or rolling over in bed ${ }^{4}$. Therefore, reliable clinical measurements of trunk movement are required to monitor the disease progress and its treatment effectiveness.

The Trunk Mobility Scale, validated by this study, evaluates PD patients in a satisfactory manner. It was showed that TMS is an easy and fast application scale. When compared with UPDRS scores, TMS shows strong correlation with that. UPDRS-III is a widely applied scale to evaluate motor PD symptoms ${ }^{23}$. However, it practically evaluated only appendicular rigidity. In UPDRS-III, axial mobility is only evaluated by the item that measure cervical rigidity.

The TMS presented good correlation with the H\&Y, showing highest scores in advanced stages of the disease. The Schwab \& England activities of daily living scale also presented a substantial correlation with TMS. Patients with higher scores in TMS showed more dependency to activities of daily living.

For clinical application, according to a systematic assessment of the scales utilized in PD, it has been recommended the minimum level of Cronbach's alpha of $0.70^{24,25}$. The internal consistence in this study was high, with $\alpha_{\text {Cronbach }}$ of 0.85 . This value did not change with the exclusion of any scale item and all TMS items were significantly and positively associated with total score indicating a high inter correlation between all TMS items. Therefore, the investigator's reliability of the TMS was excellent and the scale score is unlikely to present differences due to different application interpretation.

Regarding the internal structure of the instrument, the factorial analysis showed that patients presented a similar performance in the following items: side inclination, flexion, extension and sitting posture. However, regarding the rotation assessment, the results showed to be independent of the others. Patients with worst score in flexion, stretching and inclination movements and in the sitting posture analysis presented worst performance in rotation. But patients with difficulty in performing only the rotation did not necessarily present difficulties in performing the other proposed movements. Our findings agree with the literature and indicate higher and premature difficulties to perform the trunk rotation movements ${ }^{6,26}$. This is clear when we observe that the rotation movement is altered early in the $\mathrm{H} \& \mathrm{Y}$ stage of disease in comparison to the other trunk movements. Therefore, patients with less severe disease, based in H\&Y and UPDRS-III scales, may have already presented rotation impairments detected in TMS. The high proportion of subjects with early maximum rotation scores suggests a ceiling effect to rotation scores. This is dif- ferent from the observed in flexion, extension and inclination movement impairment that are present in more advanced disease.

Analysis of different categorical items of the UPDRSIII showed that the TMS scores presented a significant correlation with them. Moreover, "rigidity" item showed the strongest correlation ( $r: 0.89$ ), which emphasizes the important link between the trunk mobility and this symptom.

The performance in the TMS between controls and patients with PD, in terms of age and gender, did not show any significant difference. Therefore, the most important factor to trunk mobility reduction in this study was the presence and severity of PD, result that agrees with the literature ${ }^{18}$.

The present study showed that the TMS is a functional and reliable instrument for clinical assessment of trunk mobility. Moreover it is of easy clinical utilization and can be useful to monitoring evolution and therapeutic response in PD patients.

\section{REFERENCES}

1. de Goede CJ, Keus SH, Kwakkel G, Wagenaar RC. The effects of physical therapy in Parkinson's disease: a research synthesis. Arch Phys Med Rehabil 2001;82:509-515.

2. Schenkman M, Cutson TM, Kuchibhatla M, Chandler J, Pieper C. Reliability of impairment and physical performance measures for persons with Parkinson's disease. Phys Ther 1997;77:19-27.

3. Wolters E. Variability in the clinical expression of Parkinson's disease. J Neurol Sci 2008;266:197-203.

4. Bridgewater KJ, Sharpe MH. Trunk muscle performance in early Parkinson's disease. Phys Ther 1998;78:566-576.

5. Carpenter MG, Allum JH, Honegger F, Adkin AL, Bloem BR. Postural abnormalities to multidirectional stance perturbations in Parkinson's disease. J Neurol Neurosurg Psychiatry 2004;75:1245-1254.

6. Nikfekr E, Kerr K, Attfield S, Playford DE. Trunk movement in Parkinson's disease during rising from seated position. Mov Disord 2002;17:274-282.

7. Lang AE, Lozano AM. Parkinson's disease. First of two parts. N Engl J Med 1998;339:1044-1053.

8. Van Emmerik RE, Wagenaar RC, Winogrodzka A, Wolters EC. Identification of axial rigidity during locomotion in Parkinson disease. Arch Phys Med Rehabil 1999;80:186-191.

9. Verheyden G, Willems AM, Ooms L, Nieuwboer A. Validity of the trunk impairment scale as a measure of trunk performance in people with Parkinson's disease. Arch Phys Med Rehabil 2007;88:1304-1308.

10. Horak FB, Dimitrova D, Nutt JG. Direction-specific postural instability in subjects with Parkinson's disease. Exp Neurol 2005;193:504-521.

11. Brusse KJ, Zimdars S, Zalewski KR, Steffen TM. Testing functional performance in people with Parkinson disease. Phys Ther 2005;85:134-141.

12. Nieuwboer A, De Weerdt W, Dom R, Bogaerts K, Nuyens G. Development of an activity scale for individuals with advanced Parkinson disease: reliability and "on-off" variability. Phys Ther 2000;80:1087-1096.

13. Mak MK, Wong EC, Hui-Chan CW. Quantitative measurement of trunk rigidity in parkinsonian patients. J Neurol 2007;254:202-209.

14. Wright WG, Gurfinkel VS, Nutt J, Horak FB, Cordo PJ. Axial hypertonicity in Parkinson's disease: direct measurements of trunk and hip torque. Exp Neurol 2007;208:38-46.

15. Batavia M, Gianutsos JG. Test-retest reliability of the functional rotation test in healthy adults. Percept Mot Skills 2003;96:185-196.

16. Batavia M, Gianutsos JG. Test-retest reliability of the seated Functional Rotation Test in people with Parkinson's disease: a preliminary study. Percept Mot Skills 2004;99:259-270.

17. Schenkman M, Hughes MA, Bowden MG, Studenski SA. A clinical tool for measuring functional axial rotation. Phys Ther 1995;75:151-156. 
18. Schenkman ML, Clark K, Xie T, Kuchibhatla M, Shinberg M, Ray L. Spinal movement and performance of a standing reach task in participants with and without Parkinson disease. Phys Ther 2001;81:1400-1411.

19. Hughes AJ, Daniel SE, Kilford L, Lees AJ. Accuracy of clinical diagnosis of idiopathic Parkinson's disease: a clinico-pathological study of 100 cases. J Neurol Neurosurg Psychiatry 1992;55:181-184.

20. Fahn S, Elton, RL, and Members of the UPDRS Development Committee. Unified Parkinson's disease rating scale. In: Fahn SM, Calne D, Goldstein M (Eds). Recent Developments in Parkinson's Disease: Macmillan Healthcare Information; 1987:153-163.

21. Martinez-Martin P, Gil-Nagel A, Gracia LM, Gomez JB, Martinez-Sarries J, Bermejo F. Unified Parkinson's Disease Rating Scale characteristics and structure. The Cooperative Multicentric Group. Mov Disord 1994;9: 76-83.
22. Hoehn MM, Yahr MD. Parkinsonism: onset, progression and mortality. Neurology 1967;17:427-442.

23. Siderowf A, McDermott M, Kieburtz K, Blindauer K, Plumb S, Shoulson I. Test-retest reliability of the unified Parkinson's disease rating scale in patients with early Parkinson's disease: results from a multicenter clinical trial. Mov Disord 2002;17:758-763.

24. Gerlach J, Korsgaard S, Clemmesen P, et al. The St. Hans Rating Scale for extrapyramidal syndromes: reliability and validity. Acta Psychiatr Scand 1993;87:244-252.

25. Ramaker C, Marinus J, Stiggelbout AM, Van Hilten BJ. Systematic evaluation of rating scales for impairment and disability in Parkinson's disease. Mov Disord 2002;17:867-876.

26. Stack EL, Ashburn AM, Jupp KE. Strategies used by people with Parkinson's disease who report difficulty turning. Parkinsonism Relat Disord 2006;12:87-92. 